\title{
Analysis of Dynamic Classification Method for Emergency Material Demand
}

\author{
Zhang Yi, Hou Hanping \\ School of management, Beijing Jiaotong University, Beijing, Haidian District, 100000
}

Keywords: Emergency materials, Demand, Dynamic classification.

\begin{abstract}
. after an emergency, according to the time of the incident is different, the seriousness of the incident is different, the urgency of emergency supplies and the amount of emergency resources needed is also different. Therefore, the dynamic classification of emergency materials is very necessary and important. The use of scientific and reasonable way to conduct reasonable analysis of emergency material demand, to a reasonable arrangement and to control the allocation of emergency supplies, emergency supplies to save the time of transmission, to achieve the greatest degree of the value of emergency supplies. This paper mainly studies the influencing factors and method framework of dynamic classification of emergency materials demand.
\end{abstract}

\section{Introduction}

In the event of large-scale natural disasters such as emergencies, timely and efficient emergency rescue is essential. Scientific and rational deployment of emergency materials is a question that needs to be considered and studied.

Usually an incident may involve more than one of the affected area, which makes the location of emergency supplies increased, but the number of emergency supplies, emergency personnel, emergency transportation vehicles is limited, and sometimes may not be able to immediately meet each affected area needs, and this is the time to consider a lot of the factors, for example, the affected area required for emergency rescue time urgency, a dynamic classification of emergency material demand. The classification of emergency needs can smooth the work flow of emergency rescue and improve the utility of emergency materials as much as possible[1].

\section{Significance of dynamic classification of emergency material requirements}

The so-called dynamic emergency demand classification, refers to the occurrence of unexpected events, according to the emergencies related to location, time of the incident and the actual situation, determine the type, and the number of emergency supplies to need emergency supplies, and preset and determine the urgency of the emergency needs of each. Emergency demand dynamic classification is conducive to scientific and reasonable emergency resource scheduling, even a limited number of emergency supplies, emergency supplies can be achieved to maximize the utility of the emergency material demand; dynamic classification is favorable to the reduction of emergency supplies scheduling time; improve the efficiency of emergency rescue work; to reduce the maximum extent caused by because of the loss of emergencies[2].

In recent years, the research on the classification of emergency materials demand has been carried out in our country, and some scholars have put forward some achievements. For example, some scholars have started to create a fuzzy reasoning model for emergency materials demand analysis. According to the classification of emergency materials, other scholars calculate and draw up a set of relatively scientific and practical evaluation indicators, and combined with the application of fuzzy comprehensive evaluation method, the demand for emergency materials is graded. From the study of the classification of emergency materials demand in China, most of the research results now obtained are considered in the relative static background of the study of emergency materials demand classification. Of course, these reserves of emergency supplies, 
scheduling work has a certain reference value and guidance, but in the face of the relative complexity of the actual emergency rescue work, in the complex dynamic background, more scientific methods also need emergency supplies on persistent demand classification. Because when the emergency occurs, the demand for emergency materials and the urgency of the demand for emergency materials are in a process of adjustment and change. Study on the method of classification of emergency material demand understanding to the current demand for emergency supplies, including classification by case based reasoning through the demand of emergency materials classification, the establishment of neural network and fuzzy evaluation through the establishment of emergency supplies demand classification, in the reality of the emergency rescue work, more demand for classification of emergency rescue supplies through the case reasoning and neural network method to establish the situation, but these methods are all typical cases related to the past through imitation and query of the new situation, unusual for emergencies should be anxious in the work, special, or no way to completely solve the smooth relaxed. But the fuzzy evaluation method to set up dynamic classification of emergency material demand, to a certain extent can solve the problem that may arise in the work of the emergency supplies demand changes, but this method also has some problems, for example, this method is usually dependent on the subjective judgment, decision makers or researchers lack of accurate expression, it is difficult to achieve consistency test, even because the evaluation of too many factors cause the sensitivity of this method is not high. Through these reasons, we find that dynamic classification of emergency material requirements becomes particularly important. The research on the dynamic classification method of emergency material demand is the theoretical requirement of the scientific development of emergency materials classification research in our country. It is also the practical need to improve the efficiency of emergency rescue work and enhance the utility of emergency materials[3].

According to the demand of emergency supplies urgency of emergency supplies for different dynamic classification there are several reasons why specific: first, there is an objective situation, according to different stages of emergency rescue, emergency rescue needed for the types of materials are different, which makes the affected demand for emergency materials in different emergency rescue the urgency is also different. Therefore, in the process of transmission of emergency supplies is not simple blindly with the speed for the first thought, with the fastest speed of emergency supplies can be delivered, or should be based on scientific and reasonable steps and stages of the actual needs of the transport of emergency supplies. Secondly, after the occurrence of unexpected events, emergency rescue work has just begun, the number of emergency resources reserves are generally limited, but also in the emergency resources transportation capacity, there are also some problems, usually can not be achieved at once will need all the goods affected the first time served, so is the grading work must be carried out emergency materials according to the actual situation of the affected sites, then according to the order of priority reasonable arrangements for emergency rescue work. Then, the dynamic classification of the emergency supplies can also reduce the waste of resources in the emergency rescue work as much as possible. Not a reasonable arrangement for emergency supplies, so that the results are part of emergency materials not timely delivery to the special needs of the affected them, and a part of emergency supplies are delivered to the affected point to they are not needed, and the utility of emergency supplies is not maximized to play out. Finally, to analyze the actual situation of the affected sites, reasonable optimization, according to the time effectiveness of emergency supplies of its own scientific configuration, enhance the efficiency of emergency rescue, also needs the dynamic analysis of emergency material demand[4].

\section{The factors affecting the classification of emergency materials demand}

An important factor affecting the classification of emergency materials is the importance of emergency materials. The importance of emergency materials is the extent to which emergency materials can play a role in the process of emergency rescue. Emergency materials in the rescue process play a role in the specific performance of emergency supplies can reduce the number of 
property and even loss of life. The importance of emergency materials is closely related to the type of emergency, the time, stage, method and method of emergency rescue. Emergency response is different, the consequences are not the same, resulting in the loss of life and property of the affected points are different, so, even the same importance of emergency supplies in emergencies in different is not necessarily the same. In addition, in different stages of emergency rescue, according to the different focus of the rescue work, the role of emergency materials can not be the same, and the importance of emergency materials has also changed. The importance of emergency materials has a great influence on the classification of emergency materials. Generally, the most important emergency materials are the most urgent[5].

Secondly, another factor that affects the classification of emergency materials is the satisfaction degree of the disaster spot to the emergency supplies. The satisfaction degree of affected point of emergency supplies is refers to the contrast category and the number of emergency supplies category, quantity and actual disaster emergency materials affected point to have been served or have been distributed to the affected areas of the need of the. Emergency supplies of the affected sites meet the static data is not immutable and frozen, but with the change of the category and quantity change, disaster emergency material demand and transportation have or have served the emergency supplies and make corresponding changes. Disaster emergency supplies demand is the emergency rescue work set material security baseline basis, this demand is followed by the emergency situation, emergency supplies category characteristics and consumption speed, emergency time, the actual disaster continues to change, the scope of the disaster emergency rescue work of the actual progress of many factors such as the impact of change the material category and quantity relationship satisfaction affected point of emergency supplies and transportation or served most closely, if the relevant emergency supplies have been transported or have served the affected point can meet the demand for some time in the number, then the affected point in the short term of the emergency supplies demand is not so urgent, but not to the exclusion of the disaster because such as changes in the emergence of new requirements. The satisfaction degree of emergency materials is usually in a certain period of time, and a relatively stable demand. If the affected point satisfaction of emergency supplies is relatively high, so the degree of urgency of emergency supplies is relatively low, on the contrary, if the degree of satisfaction of the affected point of emergency supplies is relatively low, so the urgency of emergency material demand is relatively high.

Third, a relatively important factor that affects the classification of emergency materials is the timeliness of emergency materials. The timely degree of emergency materials refers to the timeliness of emergency materials and the emergency supplies in a timely manner to play a role in the rescue. The timeliness of emergency materials has a certain relationship with the stage of emergency rescue, the time of arrival of emergency materials and the characteristics of emergency materials. In different stages of emergency rescue, emergency supplies can play a role is not the same, rescue emergency supplies also may play in a stage is particularly evident in other stage may not rescue role or a small role. The dispatch time or delivery time of emergency materials also affects the timeliness of emergency supplies. If the emergency supplies can be delivered according to the preset time, the timeliness of emergency supplies are protected, can be very good to play the role of emergency rescue, on the contrary, if the emergency supplies can not in accordance with the needs of the time, can not guarantee the timeliness of emergency supplies, emergency supplies lag may seriously affect the rescue work, and even lead to new the crisis. The timeliness of emergency supplies is not quantitative or static, but changes with the passage of time and the development of time. Usually, the timeliness of emergency supplies demand higher, the urgency of emergency supplies demand is stronger, on the contrary, the timeliness requirements of emergency supplies is not too high, the urgency of emergency material demand will be relatively slow.

Fourth, another important factor that can not be ignored is the degree of substitution of emergency materials. Emergency material substitutability refers to disaster emergency supplies and emergency supplies has been played by the emergency relief role is consistent or similar, can replace the general level of emergency supplies and emergency supplies in the relevant category 
and characteristics. If there has been a disaster emergency supplies, emergency supplies and emergency supplies and the demand is similar or identical, can also meet the demand for some time and in the number, then the emergency supplies can be replaced by the relatively strong, so the demand for it is not so urgent[6].

\section{Dynamic classification of emergency material requirements}

Because after the incident occurred, there will be a lot of emergencies to deal with and solve the emergency rescue work is not a simple rehabilitation work on emergency supplies and transfer is not a simple transfer of work, emergency supplies have its urgency and urgency of emergency supplies is still in demand a kind of complex condition, according to the emergency rescue work, the development of different stages of emergencies, emergency supplies demand urgency will change, in order to enhance the scientific and reasonable allocation of emergency resources scheduling, and to improve the efficiency and effectiveness of the emergency rescue work, according to actual situation of emergency material demand and supply and dynamic evaluation of emergency material demand. The dynamic evaluation system include: disaster emergency demand analysis, disaster emergency supplies, emergency rescue, disaster analysis progress and development degree, generate new demand and supplies to guide emergency material dispatch process.

In order to establish a dynamic classification model for emergency material demand, we must have a complete and accurate understanding of the relevant factors that affect the demand for emergency materials. From the above we can understand, influence of emergency material demand classification factors include the importance of emergency supplies emergency materials and timely, the affected point of emergency supplies and emergency material satisfaction, the degree of substitutability of four important factors. According to the relevant documents of the state of emergency degree grade of emergency supplies, demand levels are divided, mainly divided into four grades, which are urgent, urgent, urgent, more generally, in the selected event level, quantitatively according to the influencing factors of emergency supplies demand, according to the weights of different factors, the establishment of calculation model. Because the weight of each influencing factor is different in each unexpected event, attention is paid to the flexible adjustment in practical application.

\section{Conclusion}

The dynamic classification of emergency materials is conducive to scientific and rational planning and scheduling of emergency materials, and it is conducive to the efficient and orderly development of emergency rescue work, which is of great necessity and importance. To set up scientific and reasonable method of dynamic classification of emergency material demand, need factors impact on the demand of emergency supplies can have a relevant understanding, select and set the relevant indicators, to improve the accuracy of the index, so that the emergency demand dynamic level data, have a clear understanding and grasp of the emergency the degree of emergency emergency supplies, and all aspects of emergency rescue have a clear understanding, and mobilize and reasonable configuration, improve the emergency rescue work efficiency, improve the efficiency of the use of emergency supplies, to minimize the adverse effects caused by emergency supplies when not, enhance the actual effect of emergency rescue and the true meaning of.

\section{References}

[1]However. Dynamic Optimization Model and Algorithm Design for Emergency Materials Dispatch[J]. Mathematical Problems in Engineering,2013,(2013-12-3), 2013, 2013(2):1-6.

[2]Guo-Qi L I. A Determination and Classification Method for Urban Emergency Logistics Demand Area[J]. China Safety Science Journal, 2012, 82(1):23-32. 
[3]Chen F, Guan J, Wang D, et al. Method for Emergency Materials Demand Forecasting in Sudden Events[J]. Journal of Transport Information \& Safety, 2014.

[4]Gu Y, Chen P. Analysis of Reserve Demand for Regional Emergency Materials[C]// International Workshop on Intelligent Systems and Applications. IEEE, 2011:1-4.

[5]Mertens P, Rugemer A, Chambon R. DYNAMIC TRAVEL DEMAND FOR EMERGENCY EVACUATION: THE CASE OF BUSHFIRES[J]. Institute of Transport Studies Working Paper, 2004.

[6]Wang H J, Wang J, Shi-Hua M A, et al. Dynamic Decision-making for Emergency Materials Dispatching Based on Fuzzy Demand[J]. Industrial Engineering \& Management, 2012. 